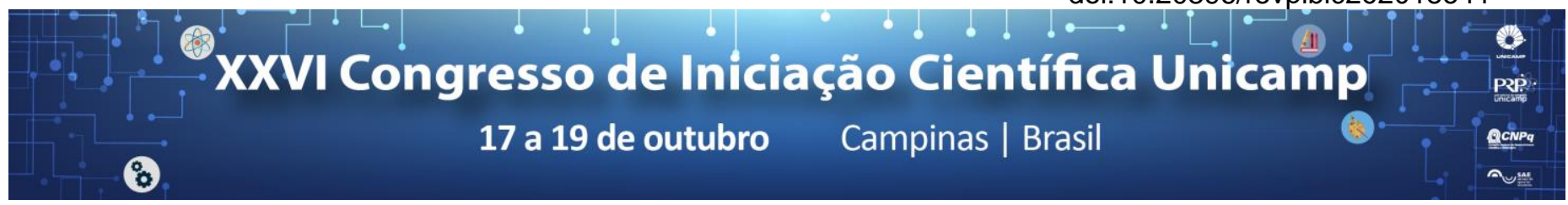

\title{
Excipient suitability for Freeze-Dryed Protein Solutions
}

\section{Giovanna Sevilha Ferreira*, Danilo Costa Geraldes, Laura de Oliveira Nascimento}

\begin{abstract}
This work focused on pre-formulation studies for freeze-dried protein formulations, using albumin as a model protein. Two aminoacids and two sugars were selected as lyoprotectors and studied according a mixture design (simplex-lattice). Sample characterization included total protein content, collapse temperature and visual inspection. Sugar formulations collapsed, but not aminoacids, which indicate non sugar excipients as the best choice under the studied conditions.
\end{abstract}

\section{Key words: \\ Lyophilization, pre-formulation, excipients}

\section{Introduction}

Proteins in aqueous diluents can be denatured by heat, $\mathrm{pH}$ changes, deamination and others; dehydration by freeze-drying is the most used process to preserve biological drugs from water related instabilities ${ }^{1}$. However, most solutions before freeze-drying must contain suitable excipients to protect the drug during dehydration ${ }^{2}$. The ingredient's suitability is analyzed in pre-formulation studies, which evaluate physical and chemical properties of drugs and excipients, isolated and combined. This analysis provides scientific foundation for the development of effective and stable pharmaceutical forms ${ }^{3}$. This work aimed to perform pre-formulation studies, using design of experiments (DoE), to evaluate lyoprotector combinations that can protect the model protein albumin.

\section{Results and Discussion}

Alanine, glycine, sucrose and trehalose were combined according to mixture design. Their collapse temperature was evaluated (freeze-drying microscopy). The collapse temperature of individual excipients was superior to -40 ${ }^{\circ} \mathrm{C}$ (alanine $-4,4^{\circ} \mathrm{C}$, glycine $-12,7^{\circ} \mathrm{C}$, sucrose $-30,2^{\circ} \mathrm{C}$ and trehalose $\left.-24,3^{\circ} \mathrm{C}\right)$, however the combination between two excipients showed a collapse temperature inferior to -55 ${ }^{\circ} \mathrm{C}$. The combination between sucrose and trehalose was the only exception, with $-42 \stackrel{\circ}{\circ}$. Bovine serum albumin was combined with excipient mixtures and the freezedrying process was carried in a 96 well plate in the pilot lyophilizer Lyostar III (SPscientific). Samples were frozen at $-55^{\circ} \mathrm{C}$, starting at $20{ }^{\circ} \mathrm{C}$, with a rate of $0,5{ }^{\circ} \mathrm{C}$ per minute. The drying process was carried with the pressure of 60 mTorr, with heating rate of $0,5^{\circ} \mathrm{C}$ to $5^{\circ} \mathrm{C}$ with holding time of 280 minutes in every $5 \stackrel{\circ}{\circ}$. Visual evaluation showed that samples containing only sucrose, only trehalose, $62,5 \%$ sucrose, $62,5 \%$ trehalose, sucrose + trehalose and only albumin collapsed. Analysis of total protein (UV/vis method) and appearance of the freezedried product (collapse, color, volume) were performed as quality parameters.
Image 1. Freeze-dried microplate of the design of experiments of bovine serum albumin and the excipients alanine, glycine, sucrose and trehalose.

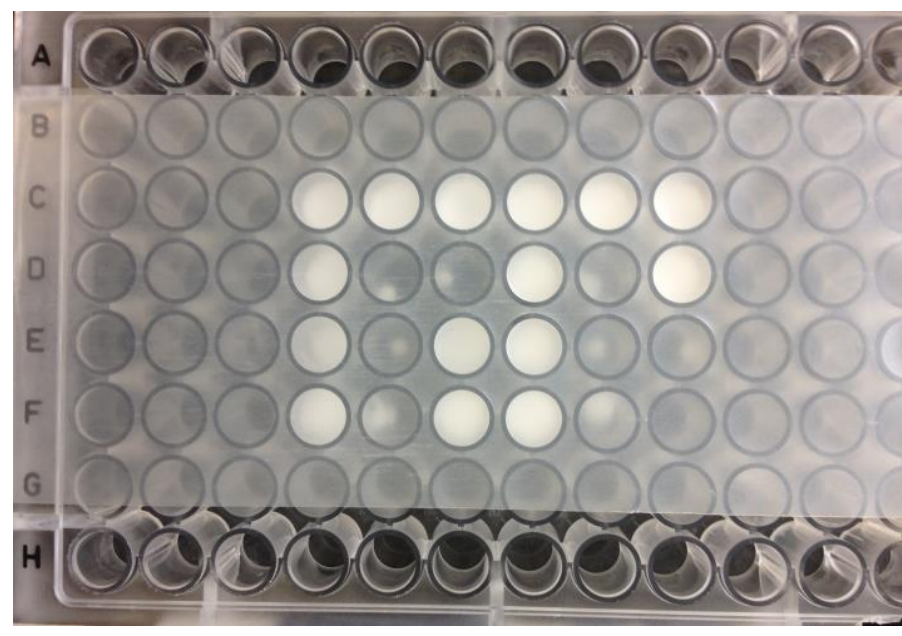

\section{Conclusions}

Combination of excipients that presented the best collapse temperature were different from the combinations with albumin that collapsed after freezedrying. Collapse temperature can change after the addition of albumin and by the possible incomplete dry of some combinations that collapsed during storage. These preliminary results point to aminoacids as better excipients for albumin protection. Further studies changing residual moisture and interaction studies will be taken to confirm the results.

\section{Acknowledgement}

Acknowledgements to CNPQ and FAPESP for this work sponsorship.

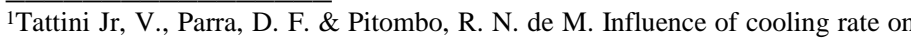
the structural and phase changes during lyophilization of bovine serum albumin. Rev. Bras. Ciênc. Farm. 42, 127-136 (2006).

2 Carpenter, J. F., Izutsu, K., Randolph, T. W. Freeze-Drying/Lyophilization of Pharmaceutical and Biological Products. CRC Press. 167- 197

3 Baheti, A., Kumar, L., Bansal, A. K. Excipients used in lyophilization of small molecules. (2010). 